\title{
Eduardo Remedi. In memoriam
}

\author{
Salvador Camacho Sandoval ${ }^{1 *}$
}

Camacho Sandoval, S. Eduardo Remedi. In memoriam. Investigación y Ciencia de la Universidad Autónoma de Aguascalientes. Número 68: 97-98, mayo-agosto 2016.

El 8 de febrero de 2016 falleció el doctor Eduardo Remedi, a los 67 años, un profesor e investigador que llegó dolido y aterrorizado por las atrocidades que estaba cometiendo un gobierno surgido del golpe militar de 1976 en Argentina, su país, al que siempre le profesó cariño y adonde ya no quiso regresar. La Escuela Iztacala de la UNAM y después el Departamento de Investigación Educativa del Centro de Investigación y Estudios Avanzados del Instituto Politécnico Nacional (DIE-CINVESTAV-IPN), en México, le abrieron las puertas para enseñar e investigar.

Sus intereses fueron los estudios sobre currículum, la formación e identidad de los docentes, historia de la educación, los científicos y sus trayectorias académicas, la educación indígena y, entre otras líneas más, la producción y transmisión del quehacer científico. Por su amplia producción académica llegó a obtener el nivel III del Sistema Nacional de Investigadores, una distinción poco común en las instituciones de educación superior y los centros de investigación en el país.

Recientemente salió al público el libro póstumo realizado en coordinación con Rosalba Ramírez: Los científicos y su quehacer, editado por la ANUIES en su Biblioteca de la Educación Superior. Se trata de un conjunto de textos de especialistas nacionales y extranjeros preocupados por comprender las trayectorias, producciones y prácticas científicas de quienes han dedicado parte de su vida a la generación y transmisión de conocimientos nuevos y especializados. Su consulta es obligada para quienes estén interesados en conocer el mundo de los científicos y la ciencia. Con estos y los temas arriba señalados asesoró a decenas de estudiantes de maestría y doctorado, dentro y fuera del país.

\footnotetext{
Departamento de Educación, Centro de Ciencias Sociales y Humanidades, Universidad Autónoma de Aguascalientes.
}

* $\quad$ Autor para correspondencia: scamacho@correo.vaa.mx

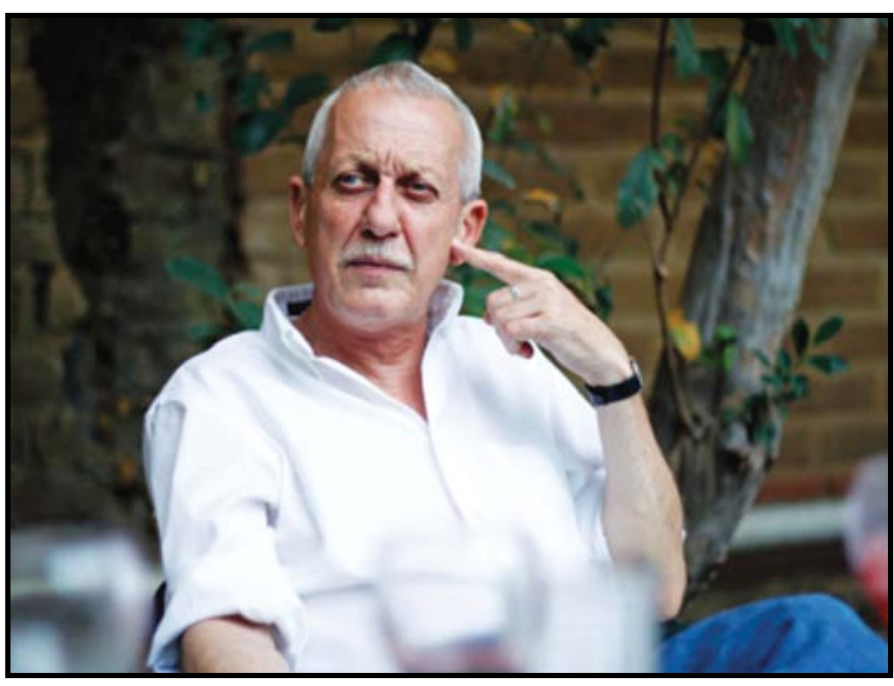

Eduardo Remedi. Fotografía de Germán Álvarez Mendiola tomada de http://www.rimac.mx/eduardo-remedi-1949-2016/

Eduardo Remedi fue mi profesor en 1986 y 1987 en la Maestría en Ciencias, con especialidad en Educación, en el DIE en la Ciudad de México. Me llamó la atención de inmediato su personalidad explosiva e irreverente, y no fui el único de sus alumnos que se sorprendió, además, por su inteligencia aguda y mordaz. No podía ocultar su raíz cultural argentina ni sus convicciones freudianas para hacer interpretaciones, no sólo de la educación en México, sino también de los mexicanos y, por ende, de sus estudiantes. Yo era de la "provincia conservadora", reprimida y religiosa; él era orgullosamente cosmopolita y representaba el estereotipo del argentino arrogante con aires de autosuficiencia y erudición. Reconozco ahora mis actitudes defensivas y de inhibición ante un profesor explosivo e hipercrítico que no solo se limitaba a enseñar contenidos en el salón de clases.

Sus concepciones sobre la educación y la docencia las ponía en práctica al momento 
de relacionarse y trabajar con sus alumnos, pues propiciaba el intercambio y la convivencia no siempre armoniosa de "subjetividades", donde estudiantes y maestro tomaban posiciones diversas y en ocasiones contradictorias, aun sin verbalizarlas. Su experiencia y conocimiento del psicoanálisis le daban una habilidad especial, al grado de que llegábamos a sentir que nos hacía "acupuntura psicológica" y se enteraba de nuestros vacíos y temores para usarlos en sus propósitos educativos, formativos.

Yo había tenido buenos maestros en la Licenciatura en Ciencias y Técnicas de la Educación en la Universidad Autónoma de Aguascalientes, los cuales me enseñaron también y quizá sin proponérselo una ética formal vinculada al cristianismo y, particularmente, a la Teología de la Liberación; y no era casualidad, pues no pocos de ellos habían pasado por un seminario. En la maestría me asomé a una puerta donde se veía la educación desde otra perspectiva, quizá igualmente crítica y propositiva, pero muy liberal y, con Eduardo, iconoclasta e intencionalmente afectiva.

No olvidaré la impresión que me llevé al entrar a su departamento para disfrutar de una fiesta que había organizado para sus alumnos. Eduardo era un profesor joven de 38 años y yo un estudiante de 28. Como un psicólogo freudiano clásico en ese entonces, apegado a la centralidad del Sexo en el desarrollo de la personalidad del sujeto, Eduardo había decidido hacer de su departamento un minimuseo del erotismo y la sexualidad. (¿ Tendría razón Freud cuando dijo que en temas de sexualidad, somos actualmente, todos nosotros, enfermos o sanos, nada más que hipócritas?). Esa exposición en su hogar era bella, porque Eduardo tenía un gusto artístico fino por la música, la literatura y las artes plásticas, mismo que venía cultivando desde sus años estudiantiles en su querida Córdova, Argentina.

Como alumnos de Eduardo Remedi aprendimos con sus teorías y su praxis cotidiana que la educación es tan compleja y cambiante como lo es la persona en sí misma y en su relación con los demás. Desde la perspectiva de algunas personas que también lo conocieron, su trato no siempre era cordial. Una de sus colegas, Alma Dzib Goodin, fue advertida cuando le dijeron que iba a trabajar con él: "No llegue tarde a la reunión", "no te molestes con sus comentarios, puede ser misógino", "es argentino, no esperes que sea amable contigo". Finalmente, al tratarlo y conocerlo un poco más, el estereotipo se derrumbaba de inmediato y surgía el verdadero Eduardo: un hombre cálido, generoso y dispuesto a compartir la sonrisa o la broma desparpajada por la vida. Era el "soñador despierto" que conocí a fines de los años ochenta.

En estos tiempos convulsos donde se discuten los rumbos de la educación, el papel del magisterio y la responsabilidad social de los científicos en México y el mundo, la voz inteligente y crítica de Eduardo Remedi nos hace falta, como nos hace falta su actitud desenfadada y alegre, y también su postura esperanzadora.

Descansa en paz, Maestro. 